\title{
Corpus-driven insights into the discourse of women survivors of Intimate Partner Violence
}

\author{
El discurso de mujeres supervivientes de violencia de género: \\ incursiones lingüísticas basadas en un análisis de corpus
}

\begin{abstract}
Alfonso Sánchez-Moya
Universidad Complutense de Madrid/Vrije Universiteit Amsterdam. asmoya@ucm.es Received: 30/04/2017. Accepted: 11/10/2017
\end{abstract}

\begin{abstract}
Despite its ubiquity, Intimate Partner Violence (IPV) is still under-researched from a Critical Discourse Studies (CDS) perspective. Thus, this paper investigates the discourse of women survivors of IPV focusing on a corpus-driven examination of the data. This is done after applying the text-analysis software tool LIWC (Linguistic Inquiry and Word Count) to a 120,000-word corpus collected from an anonymised, public, online forum available to IPV survivors. I contrast a plethora of linguistic phenomena in three online communities embedded within this forum ("Is it Abuse?", "Getting out" and "Life after abuse") in the attempt to sketch out how the discursive output varies across these three stages. This paper shows how pronominal distribution plays a role in the forging of collective identity. Differences in the emotional tone across the three explored groups are also identified. Useful though these corpus-driven pointers may be, this study also warns of the precaution with which findings solely deriving from quantitative analyses need to be treated.
\end{abstract}

Keywords: intimate partner violence (IPV); digital discourse; CDS; corpus; LIWC.

Resumen: A pesar de su ubicuidad, la violencia de género es un campo aún poco explorado desde la perspectiva de los Estudios Críticos del Discurso. Este artículo investiga el discurso de mujeres supervivientes de violencia de género poniendo el foco en un análisis basado en el estudio de un corpus. Se efectúa tras aplicar LIWC (Linguistic Inquiry and Word Count) a un corpus de 120.000 palabras de un foro en línea, público y anonimizado disponible a supervivientes de violencia de género. Se contrastan varios fenómenos lingüísticos en tres comunidades digitales de este foro (“¿Es abuso?”, "Dejando una relación abusiva" y "La vida después del abuso") en el intento de esbozar cómo la producción discursiva varía en estas etapas. Este estudio muestra cómo la distribución pronominal es relevante en la forja de la identidad colectiva. Se identifican

》Sánchez-Moya, Alfonso. 2017. "Corpus-driven insights into the discourse of women survivors of Intimate Partner Violence". Quaderns de Filologia: Estudis Lingüistics 22: 215-243. doi: 10.7203/qf.22.11309 
también diferencias en el tono emocional de estos tres grupos. A pesar de su utilidad, esta investigación advierte de la precaución con la que lidiar con resultados procedentes únicamente de análisis cuantitativos.

Palabras clave: violencia de género; discurso digital; Estudios Críticos del Discurso; corpus; LIWC. 


\section{Introduction}

Based on the intersections of critical discourse studies (CDS), a corpus-driven analysis, and the exploration of a sociological phenomenon such as Intimate Partner Violence (IPV henceforth) from a discursive perspective, this article seeks to provide insights into the discourse used by women in a publicly-accessible online forum that fosters the exchange of posts around this type of violence. Given the affordances of the site under scrutiny, and by employing corpus-assisted research, this study pursues to gain a better understanding of IPV as a social phenomenon by evaluating the linguistic choices made by users of this forum. To wit, I shall investigate the differences in language use among three of the different online communities nested within this site: 'Is it abuse?', 'Getting Out', and 'Life after an abusive relationship'. By doing so, I arguably establish a correlation between these three communities and different stages within an abusive relationship in the attempt to sketch out how the discursive output varies across these three stages. This is operationalised by running a LIWC analysis to a corpus consisting of 120,000 words (40,000 words per each of the above-mentioned communities) and by later contrasting the distribution of words as grouped in linguistic categories provided by LIWC (\%) that characterise the three online communities.

This paper is organised as follows: Section 2 offers a succinct overview of core concepts in this paper and how they are understood (namely IPV, discourse and CDS and Corpus Linguistics (CL)). Section 3 considers the most salient methodological considerations, placing an emphasis on LIWC, the text-analysis software tool being used for carrying out my analysis. Section 4 engages with the presentation of the findings, in addition to discussing their implications. Finally, Section 5 gives concluding remarks, identifies limitations and draws possible lines for future research.

\section{Theoretical preliminaries: the exploration of IPV from CDS}

Asserting that violence is widely spread across most societies and cultures is certainly unproblematic, especially when violence is regarded one of the most salient global public health problems nowadays (WHO, 2016). Trying to provide a definition of both the phenomenon and the 
many related issues around it, however, is not at all cut and dried. This is partly rooted in the difficulty when conceptualising violence per se. In fact, as suggested by sociological research in these lines, determining the boundaries of what stands for violence and not-violence is hard, especially in practice (Krug, Dahlberg, Mercy, Zwi and Lozano, 2002; Walby, Towers et al., 2017). Reasons for this are multiple and are related to, inter alia, whether violence is actual, intended or threatened, the diverse interpretations of concepts such as harm, or the repetition of violent events (Walby, Towers et al., 2017). Not surprisingly, this conceptual fuzziness has triggered methodological divergences when trying to provide reliable accounts of violent events (Walby, Towers et al., 2017).

Nonetheless, it can be arguably stated that Intimate Partner Violence (IPV) is one of the most salient types of abuse addressed against women (Heise, 1998). Contrary to more collective and multi-layered forms of violence against women (VAW), IPV is characterised for its interpersonal character in the sense that violence largely takes place between family members and intimate partners in wide range of settings, mostly in private contexts (Krug et al., 2002:6). Straightforward though this may seem, the mere attempt of providing a unique definition of IPV as a phenomenon is far from finding an agreement, which gives an idea of how slippery this endeavour might be. In fact, although I adhere to the understanding of IPV as a gendered phenomenon, many scholarly voices have challenged the assumption that IPV is a gender-driven phenomenon. According to these views, this is linked to higher victimisation rates among women (Nicholls and Dutton, 2001) which may be related to conservative ideas around manhood and a consequent under-reporting of abuse by male victims (Dutton and Nicholls, 2005) or the tendency to believe that violence initiated by women is treated differently because it results in less serious physical harm on male partners than vice versa (Ross and Babcock, 2009). Although I believe that the rather ill-defined boundaries of some violent acts play a significant role in what accounts for violence - especially when it comes to psychological abuse, for instance, as argued by Winstok and Sowan-Basheer (2015), there is solid evidence to claim that IPV is strongly influenced by the gender variable (Harris et al., 2012). Global institutions have widely observed that "the overwhelming global burden of IPV is borne by women" (WHO, 2016), so much so that 1 in 3 (35\%) women worldwide 
can be alleged to have experience IPV in their lifetime (WHO, 2016). In the attempt to provide a more proximate depiction of this situation in the context where this research is framed, it is noteworthy to mention that $46 \%$ of female homicide victims in England and Wales between 2013-2014 were killed by a male partner or ex-partner in contrast with $7 \%$ of male victims by a female partner during the same period (Office for National Statistics, 2015).

Interesting though discussions around these concepts may be, further engagement with them would fall outside the scope of this article ${ }^{1}$. Notwithstanding the controversies around this type of violence, and based on previous studies (Crowell \& Burgess, 1996; Heise \& García-Moreno, 2002), I understand IPV as multiple, non-mutually exclusive acts of controlling, coercive, threating, degrading or violent behaviour within an intimate relationship triggered by a partner or ex-partner that causes physical, psychological or sexual harm to those in the relationship. As may be noted, I refrain from using a gender-based definition of IPV. By no means does this imply I do not recognise the gender dimension within IPV. Rather, the main motivation for this is that this approach lends itself more suitably to also deal with this type of violence in homosexual partnerships, where the application of gender standards is not always so straightforward. Nonetheless, this piece of research concentrates in heterosexual relationships in which violence is exerted in women by the male counterpart in the relationship.

Awareness-raising around IPV was brought about partly as an aftermath of the second wave of feminism back in the 1980s. Since then, there have been serious attempts to tackle this issue from a multiplicity of angles. From an institutional standpoint, after the United Nations Declaration on the Elimination of Violence Against Women in 1993, efforts to define gender violence as a particular type of violence crystallised, providing a taxonomy of different types therein, and a systematic encouragement to eradicate it in any of its possible manifestations. Not unexpectedly, academic work has similarly contributed to providing a more accurate understanding of IPV in a plethora of possibilities, a small representation of which I move on to briefly mention now. Al-

\footnotetext{
${ }^{1}$ For a brief illustration on the multiple attempts to understand IPV, albeit advocating that no single theory can fully explain the phenomenon of IPV, see Ali and Naylor (2013).
} 
though research on the sociological (and worldwide) dimensions of IPV is extensive (Dobash and Dobash, 2015), many others have also examined the connections between IPV and physical (Campbell, 2002), psychological (Kumar et al., 2013) and reproductive health (Dartnall and Jewkes, 2013). Furthermore, as a positive outcome of the institutional claims, the legal facets of IPV have been widely investigated too (Walker, 2015).

Interestingly, a great proportion of studies taking IPV on board suggest that their main motivation is to be conducive to deeper insights into this social phenomenon, therefore implying that there is still much to be done in these lines. Research from the language sciences have also echoed this pressing need, giving rise to a growing body of research investigating how the forms in which linguistic issues and IPV are intertwined. One observable trend deals with discourses of/about IPV, mostly focussing on recontextualised representations of both IPV and key social actors typically involved in it (namely abused women and their abusive male partners) in media discourse (Santaemilia and Maruenda, 2014) or online environments (Bou-Franch, 2013). Necessary though these studies are, attempts to examine discourses by social actors in IPV contexts are somewhat less frequent to date. This may be related to the complexity of gathering data, given the sensitive nature of this issue. Nonetheless, explorations of the macro-level of discourse in IPV contexts have drawn thought-provoking conclusions that can be of valuable help to gain a richer comprehension of IPV and social actors therein (Baly, 2010). Boonzaier (2008), for example, identifies the traces of "femininity discourse" in narratives of abused women, which underpins the loving, caring and nurturing roles of women that partly affect these women's self-construction as the ones to blame for the situation. This paucity of research becomes even more remarkable when studies on the micro-level of discourse are concerned. In fact, although studies relying on a more detailed linguistic operationalisation have analysed an array of discursive structures in the representation of IPV episodes (Stokoe, 2010), I would argue that discourse-driven approaches to women suffering from IPV and their self-reported experiences around it are still under-researched.

In fact, it is striking to observe that IPV has not gained sufficient attention from Critical Discourse Studies, a field that has been traditionally characterised, inter alia, for analysing "opaque as well as trans- 
parent structural relationships of dominance, discrimination, power and control as manifested in language" (Wodak and Meyer, 2009: 10). This view is partly possible due to the conceptualisation of discourse as socially constitutive as well as socially conditioned (Fairclough and Wodak, 2004), which turns discourse into a "potential and arguably actual agent of social construction" (Sunderland and Litosseliti, 2002: 13) with a crucial role for creating, sustaining and/or transforming the social status quo (Hart and Piotr, 2014). These are the principles that ooze from the many social issues that have been explored through the CDS lenses, dealing with power issues in contexts related to political discourse (Marín-Arrese, 2011), racism (Van Dijk, 2015) and gender and sexualities (Baker, 2008), to name just a few. In fact, this motivation of readdressing power inequalities is a priority for CDS analysts. Similarly, CDS is also characterised by presupposing a political stance on the part of the researchers that seeks to bring about social change (Hart and Piotr, 2014). For this to be accomplished, a permanent recursivity between linguistic mechanisms (especially at the micro-level of discourse) and how these are interwoven in the fabric of the macro-(social) structures (KhosraviNik, 2010).

Although the investigation of IPV from CDS seems justified now, the outcome of this study would surely differ depending on the perspective within CDS I were to adopt when examining this social issue. As thoroughly depicted by one the latest compilations dealing with CDS (Hart and Piotr, 2014), different theoretical and methodological approaches to the study of discourse have prompted the development of multiple tool boxes from which to provide discourse-based insights into a social-driven concern. More traditional approaches (Wodak and Meyer, 2009) have been widely criticised on the basis of researchers' bias and data representativeness (Stubbs, 1997; Widdowson, 2004). This has triggered interesting reactions within the field to respond to this criticism. Both the socio-cognitive and the corpus linguistic approach can be seen as two consistent and systematic attempts to tackle some of the above-mentioned weaknesses. Interestingly, this article is somewhat embedded in the intersection of these two approaches, as I try to justify in what follows.

As Teun Van Dijk puts it,

most earlier and contemporary theories in CDS assume a direct link between discourse and society (or culture), [but] the problem is that 
the nature of these casual or similar direct relationships is not made explicit but taken for granted or reduced to unexplained correlations (2014: 121).

It is the unexplained nature of these correlations that Van Dijk attempts to solve by endorsing the socio-cognitive approach to the understanding of discourse (Van Dijk, 2014). While providing an accurate picture of this approach to discourse would challenge the space constraints of this paper, it is noteworthy to mention some of its key tenets. In short, it is claimed that the accounts in which individual language users frame text and talk is based on socially shared representations of individual social actors as members of various social collectivities, thus implying that personal and social dimensions in discourse processing are inextricably intertwined (Van Dijk, 2014). In other words, "our ongoing experience and understanding of the events and situations of our environment take place in terms of mental models that segment, interpret and define reality as we "live it" (Shipley and Zacks, 2008; Van Dijk, 2014). Mental models are therefore regarded as the "interface between discourse and the social or natural environment" (Van Dijk, 2014:124) and are given the potential of having a fundamental role in the production and comprehension of discourse. Accordingly, this approach defends

a mutually constitutive relationship between discourse and social cognition, where discourse is instantiated in texts that project and transform socio-cognitive representations (SCRs), both the discourse producers' and the recipients' (Koller, 2014:152).

What is more, socio-cognitive representations (SCRs) are "not individually held mental models, but cognitive structures shared by members of a particular group" (Koller, 2014). Consequently, they are "socially and discursively constructed in the course of ... communication [...], and are subject to 'continual transformation [...] through the ebb and flow of intergroup relations"' (Augoustinos et al., 2006: 258-259). As will be specified in the next section, this view of discourse gains more prominence if the communicative context this article pays attention to is taken into account. Rather than analysing discourse by isolated language users, I investigate how online users of an IPV forum engage in the construction of their online collective identity and the ways 
in which this is instantiated in their discursive production. This seems to fit nicely into the motivations of this approach, since as suggested indeed by Koller (2014: 153),

[a] socio-cognitive approach to critical discourse studies is well suited to analysing collective identities and is especially relevant at the interpretation stage of analysis, which addresses the questions as to why text producers have selected a range of linguistic devices to construct groups in a particular way.

As anticipated before, CDS research has been criticised for a lack of rigour in both collecting and analysing data, accusing studies in the field of cherry-picking and questioning issues of representativeness and randomness in data selection (Widdowson, 1998; 2004). In the attempt to neutralise these arguments, CDS have gradually drifted towards a reliance on the corpus linguistic approach, which are well suited for identifying ideological patters of texts that would otherwise remain unnoticed (Baker, 2006). Another interesting contribution of the corpus linguistic approach pertains to the possibility of enabling the researcher to examine the texts under analysis without preconceived notions regarding the content of selected data (Baker et al., 2008). Despite its multiple strengths, it is also important to bear in mind that an over-dependence on the corpus linguistic approach may also have undesirable consequences for a CDS-oriented study. As pointed out by Fairclough, corpus linguistics (CL) can be arguably criticised for a positivist reduction of the 'actual' to the 'empirical' or 'the observable' (2015: 22), exposing CDS research to losing its character and purpose and to the risk of being too constrained by the capacities of CL (2015: 23). This is of particular significance in CDS, since many power imbalances are discursively crafted in ways that are not textually explicit, becoming therefore invisible for CL software (Fairclough, 2015). As far as this article is concerned, I use a text-analysis software tool to provide a solid starting point for my research purposes. On no account should this be regarded as a definite exploration of my data, which would very much require a more in-depth qualitative investigation.

Overall, this section has sought to underpin the theoretical foundations of this study, which is embedded at the crossroads of CDS, IPV and CL. As already discussed, taking into account the motivations behind CDS research, the exploration of a social phenomenon such as IPV 
from a socio-cognitive approach to discourse is deemed feasible. I assist my analysis by making use of a software tool (LIWC) and therefore falls within CL, although I understand this application as a very initial procedure that needs to be complemented by a closer examination of the data.

\section{Methodological issues}

\subsection{Data and data collection}

This article is based on data collected from a publicly-accessible online forum, hosted by a British charity with an outstanding determination to provide support and resources of many sorts to both women and their offspring when undergoing IPV. Although this type of data can be regarded as sensitive due to its content, the corpus analysed here is believed to respect principles of research ethics and ethical treatment of persons as promulgated by key documents in this area (Markham and Buchanan, 2012). Data under investigation here was collected from an online forum where users are warned of the live, public character of the site. Posts were therefore collected without the need of registering in the site. Although my research interests comply with the socio-cognitive character of this type of discourse and are less concerned with individual discourse usage per se, users are completely anonymised and posts are moderated online, making sure that the revealing of personal details cannot become a potential risk to the human being behind the online persona. Nonetheless, discussions around internet-based data are still vivid and currently being developed (Nissenbaum, 2010).

The analysis presented here is based on a corpus collected in two different time spans to guarantee a richer discursive outcome (December 2014 - March 2015 and December 2015 - May 2016). Despite the fact that studying the interaction generated from the exchanging of messages would surely yield interesting data, this corpus only consists of posts which are the first in the thread they belong to. Reasons behind this deal with the primary purpose of my research, which is interested in how the perpetrator is referred to in these posts for the first time. The assumption that the activation of the perpetrator in the first post of a thread would likely influence the mechanisms used in following posts, cross-post interaction has not yet been considered. In the attempt 
to contrast the discursive production within the online forum, the total amount of words was collected from three out of the many online communities in the same site. Accordingly, 40.000 words were collected from 'Is it abuse?' (122 unique posts), 'Getting Out' (163 posts), and 'Life after an abusive relationship' (187 posts) respectively, resulting in a total of 120.000 words. These three communities are frequently referred to SB1, SB2 and SB3 respectively. Full posts from the three communities are included in Table 1 below in the attempt to illustrate the type of discourse under investigation.

\begin{tabular}{|c|c|}
\hline $\begin{array}{c}\text { Forum } \\
\text { community }\end{array}$ & Illustrative post \\
\hline SB1 & $\begin{array}{l}\text { What is abusive? Is it when they constantly need u around his } \\
\text { relative is v I'll and he's saying he needs me someone close } \\
\text { however I need to work night shifts so I'm knackered and } \\
\text { I'm stressed myself [sad_emoji] I feel bad I'm not with him } \\
\text { after my nights but he can't sleep and he's snappy cos he's } \\
\text { upset he tells me I'm selfish sometimes wen I don't come } \\
\text { over I just feel like a realty bad girlfriend I can't take time } \\
\text { off cos I've taken time off not so long ago for a death in my } \\
\text { own family and I was sick few times plus my work he has } \\
\text { been violently abusive towards me before snd actually gave } \\
\text { me somewhere to live so it's not a good look.... Advice and } \\
\text { suggestions }\end{array}$ \\
\hline SB2 & $\begin{array}{l}\text { i'm having to flee again } \\
\text { need to pack up \& start again as he crushed my life again } \\
\text { this time trying to do it all with laughter } \\
\text { anyone got any practical tips on the subject ov securing } \\
\text { permanent housing as feel } 2 \text { mentally unstable to mix with } \\
\text { people but need new start \& } 2 \text { rocky to think practically }\end{array}$ \\
\hline SB3 & $\begin{array}{l}\text { Its been almost (information removed by moderator) months } \\
\text { and i can honestly say i've broken the seal he used to brain- } \\
\text { wash me to the point i stopped drinking and going out so- } \\
\text { cially although i have not mastered the going out to town } \\
\text { with the gorls bit yet i finally felt confident safe and unguilty } \\
\text { to enjoy myself over the new year and with friends i aint seen } \\
\text { in ages! Massive sigh of relief! I had my first few drinks in a } \\
\text { year! X }\end{array}$ \\
\hline
\end{tabular}

Table 1. Illustrative posts collected from the three forum communities 


\subsection{Applying LIWC to the analysis of discourse by IPV survivors}

Given the pressing need of counteracting claims of cherry picking in CDS (Hart and Cap, 2014), there has been a gradual increase in the use of software tools to scrutinise texts within the field in particular and applied linguistics in general. Although not as widely spread as software used for similar purposes (such as AntConc, WMatrix or Sketch Engine), Linguistic Inquiry Word Count (LIWC henceforth) was developed by a team of social psychologists led by James Pennebaker at the University of Texas. In short, LIWC is a programme for quantitative text analysis that relies on word count strategies to investigate issues concerned with content analysis and style. It is based on the assumption that lexical choices made by people transmit psychological information over and above their literal meaning and independent of their semantic context (Pennebaker et al., 2007), which can at the same time be used to make inferences about dimensions of individuals' personalities (Tausczik and Pennebaker, 2010).

This tool processes speech samples by identifying and classifying them according to the three internal dictionaries that the LIWC2015 version has, which consists of almost 6.400 words, words stems and selected emotions (LIWC, 2017) ${ }^{2}$. LIWC software provides the percentage-use indices of 80 standard linguistic categories of different types as they are represented in the scrutinised texts submitted by the LIWC user. Apart from the word count of each file, this data record includes 4 language variables (analytical thinking, clout, authenticity, and emotional tone), 21 standard categories identifying function words ( $\%$ of pronouns, articles, auxiliary verbs, etc.), 41 semantic categories dealing with psychological constructs (such as affect, cognition, biological processes). Additionally, although not so central for the motivation of this study, information is supplied regarding informal language makers (assents, fillers, swear words) or punctuation categories (periods, commas). Broadly speaking, this output measure is correlated to both personality and real-world outcome measures, which arguably capture people's social and psychological statuses as represented in their discursive production.

\footnotetext{
${ }^{2}$ This paper is based on LIWC 2015 version. More details on the development and psychometric properties of it can be found in Pennebaker et al., 2015.
} 
LIWC has been applied to language-driven research in combination with more social-oriented issues. Generally speaking, Pennebaker (2011) has suggested that the frequency with which people engage in the use of word categories can be directly linked with issues of power and social class or people's degree of social connectedness. More specifically, LIWC has been used in educational settings in order to predict final course performance based on the difference in thinking styles by comparing high-performing students with low-performing ones (Robinson, Navea and Ickes, 2014). Additionally, perhaps closer to my research interests, LIWC has also been employed to scrutinise political discourse, using the software tool to try to measure aspects of personality dimensions in political speeches (Slatcher et al., 2007; Kangas, 2014).

Nevertheless, to my knowledge, the investigation of online accounts of IPV by employing LIWC has not been endeavoured yet. Rather than focussing on how LIWC categories would reflect individuals' real-world measures, I was interested in observing if the distribution of word categories would vary if the above-mentioned communities within the same online forum were to be contrasted. To this end, I submitted each set of 40.000 words to LIWC, obtaining as a result the percentage of words belonging to each of the already-given categories provided by LIWC. Although it is possible to think of some limitations to this (which shall be explored in the final section of this article), by doing so I sought to shed light on the bigger discursive picture of these three online sub-communities. Therefore, my main aim was to obtain a preliminary approximation to the discursive character of these three groups based on the LIWC categories, observations that would certainly need to be considered from a more contextualised perspective of the analysed discourse via a qualitative-driven exploration of the data. All things considered, this piece of research is guided by the following research questions:

1. How can the application of text-analysis software tools such as LIWC contribute to better understand the online discourse of women undergoing IPV-related experiences?

2. How can LIWC-provided categories shed light on the discursive characterisation of the three communities nested in the IPV online forum under scrutiny? 


\section{Analysis and discussion}

This section presents the percentage-use indices of those LIWC categories that are deemed to be more pertinent for the purposes of this study. In fact, the output of these LIWC categories are used to organise this section in several subsections, which present and discuss the implications of those percentages for the social issue under investigation. It is worth pointing out that statistical treatment of these figures is complex given that this study does not account for individuals' discursive production but, rather, it understands the language production in each of the three analysed categories as embedded in the socio-cognitive approach to discourse. Nonetheless, note that the number of words in each of them is always the same (40.000), enabling thus the contrast between them. For discussion purposes, I normally take the online community including users writing about life after abuse (SB3) as a reference, paying special attention to increasing or decreasing patterns if the other two are considered.

\subsection{Language variables: analytical thinking, clout, authenticity and emotional tone}

Among the many categories LIWC uses to classify words, there are six of them that fall within the group "summary language variables" (Pennebaker et al., 2015). It is possible to obtain information about the words per sentence (WPS), the percentage of words with less than six letters (Sixltr) or find out about those which appear in LIWC dictionaries $(D i c)$. Although these categories have been used by research to trace correlation between them and the complexity of thinking styles, in this article I will be focussing on the remaining four: analytical thinking (Analytic), clout (Clout), authenticity (Authentic) and emotional tone (Tone). Quite remarkably, these four categories are based on findings from previous research carried out by the developers of the tool, references to which will be pointed out accordingly.

It may be useful to briefly explain these four categories. First, the category analytical thinking is thought to capture the extent to which words may indicate formal, logical and hierarchical thinking patterns (LIWC, 2017, Pennebaker et al., 2014). Results from educational contexts have put forward that a low percentage in this category may im- 
ply using language in more narrative ways, focussing on the here-andnow and leave more room for personal experiences (Pennebaker et al., 2014). Second, clout refers to "the relative social status, confidence, or leadership that people display through their writing" (LIWC, 2017, Kacewicz et al., 2013), a high number suggesting a more expert and confident style whereas a low number would indicate more tentative or even anxious style (Pennebaker et al., 2014). Third, the algorithm for authenticity derives from a series of studies indicating that when people reveal themselves in authentic or honest ways are prone to be more personal, humble, and vulnerable (LIWC, 2017; Newman et al., 2003). Fourth, emotional tone seems to be more straightforward in interpretative issues, since the higher the percentage, the more positive the tone (LIWC, 2017; Cohn et al., 2004).

Having considered these categories and what they stand for, it seems timely to present the outcome measures (\%) for the analysed corpus. As illustrated in Table 2 below, two different tendencies can be observed if both the forum communities and the summary language variables are compared. On the one hand, especially if the first and third stages are compared, there is an increase in categories referring to analytical thinking $(+2,88 \%)$, emotional tone $(+7,84 \%)$, and authenticity $(+13,76 \%)$. On the other hand, the clout category seems to behave differently, with a higher percentage of words in the first community than in the third one $(-8,38 \%)$.

\begin{tabular}{|c|c|c|c|c|}
\hline \multirow{2}{*}{$\begin{array}{c}\text { Forum } \\
\text { communities }\end{array}$} & \multicolumn{4}{|c|}{ Summary language variables (LIWC) } \\
\cline { 2 - 5 } & Analytical & Clout & Authenticity & Tone \\
\hline $\begin{array}{c}\text { SB1 } \\
\text { 'Is it abuse?' }\end{array}$ & 17,61 & 48,21 & 62,72 & 6,23 \\
\hline $\begin{array}{c}\text { SB2 } \\
\text { 'Getting out' }\end{array}$ & 18,45 & 41,42 & 70,50 & 10,59 \\
\hline $\begin{array}{c}\text { SB3 } \\
\text { 'Life after abuse' }\end{array}$ & 20,49 & 39,83 & 76,48 & 14,07 \\
\hline
\end{tabular}

Table 2. LIWC summary language variables (in \%)

If the brief considerations above are taken into account, one of the most notable contrasts is observed when the emotional tone of these three communities is considered $(+7,84 \%)$. Quite expectedly, LIWC 
can be employed to suggest that women writing in 'Life after abuse' show a more positive emotional tone than those contributing to 'Is it abuse?', an observation which was somewhat expected. Furthermore, it can be argued that discourse in the 'Life after abuse' subcorpus responds to a more analytical pattern than discourse in 'Is it abuse?'. A lower percentage in the latter may therefore point out a stronger focus on the here-and-now and on personal experiences, together with a tendency to offer more narrative accounts of these users' experiences with IPV. The tendency to express themselves in more personal and humble ways is also reinforced by the higher percentage measuring authenticity found in the third community, which additionally represents the most noticeable contrast $(+13,76 \%)$ if these four LIWC categories are taken into account. Surprisingly, though, this would also suggest a greater degree of vulnerability among users of this community. Neither had I foreseen a weaker percentage for the category clout in the third subcorpus, especially because this could be seen as a characteristic of more tentative, humble or even anxious style. These results would be at odds with my original expectations and would also contradict results in some other categories that will be discussed later in this paper.

\subsection{Pronominal distribution}

It goes without saying that a critical approach to the study of pronouns has been traditionally central for CDS research, since they can convey key information concerning issues of power and dominance (Van Dijk, 1993). As a result, given that they are frequently used as remote sensors of group dynamics (Kacewicz et al., 2012), pronouns are at the core of studies willing to draw conclusions on the discursive construction of collective identities (Koller, 2008) since they can be used to identify focus, priorities and intentions (Tausczik and Pennebaker, 2010). Not unexpectedly, LIWC caters for this need in any language-driven inquiry and provides percentages for a wide range of pronominal information. There is an interesting number of findings deriving from the application of LIWC to social issues. For instance, it seems to be a correlation between people who are undergoing physical or emotional pain and a higher tendency to use first-person singular pronouns (Rude, Gortner \& Pennebaker, 2004). In a similar vein, studies have also shown that couples using the first-person plural pronoun proved to assess the qual- 
ity of their marriage more positively than those who did not (Simmons, Gordon and Chambless, 2005). More broadly speaking, research combining LIWC and pronouns has also explored political (Gunsch et al., 2000) and academic discourses (Kowalski, 2000).

Table 3 below depicts the percentages offered by LIWC once the three subcorpora under scrutiny were processed. It is worthwhile to mention though that figures to indicate the percentage of 'he' needed to be measured by AntConc (Anthony, 2014), since the version of LIWC used for this analysis makes no difference between he and she. This can arguably be seen as one of the major shortcomings of the tool. Notwithstanding this limitation, LIWC can provide interesting insights into the way pronouns are used across the three subcorpora. Based on the data, it is possible to observe the general use of personal pronouns is less salient in 'Life after abuse' (-1.24\%), especially if both the first and third stages are juxtaposed. A similar pattern is observed in the case of he $(-1.62 \%)$ and we $(-0.14 \%)$. However, the use of the first-person pronoun $I(+0.39)$, the pronoun you $(+0.12 \%)$ and instances of they $(+0,25 \%)$ do increase in SB3 if SB1 is considered.

\begin{tabular}{|c|c|c|c|c|c|c|}
\hline \multirow{2}{*}{$\begin{array}{c}\text { Forum } \\
\text { communities }\end{array}$} & \multicolumn{7}{|c|}{ Pronouns (LIWC) } \\
\cline { 2 - 7 } & PPRON & I & WE & YOU & HE & THEY \\
\hline $\begin{array}{c}\text { SB1 } \\
\text { 'Is it abuse?' }\end{array}$ & 17,47 & 9,53 & 0,86 & 0,48 & 3,84 & 0,45 \\
\hline $\begin{array}{c}\text { SB2 } \\
\text { 'Getting out' }\end{array}$ & 16,77 & 9,91 & 0,78 & 0,41 & 2,82 & 0,43 \\
\hline $\begin{array}{c}\text { SB3 } \\
\text { 'Life after } \\
\text { abuse' }\end{array}$ & 16,23 & 9,92 & 0,72 & 0,60 & 2,22 & 0,70 \\
\hline
\end{tabular}

Table 3. Pronominal distribution (in \%)

The way in which pronouns are used across these forum communities may have several interpretations, as suggested by the variation in percentages shown in Table 3 above. As far as the use of the first-person pronoun is concerned, there is a higher tendency to make use of it when users post in 'Life after abuse'. Based on similar studies (Rude, Gortner $\&$ Pennebaker, 2004), this would suggest a higher index of psycholog- 
ical and emotional distress in stages where abuse has been somewhat internalised, since many posts in 'Is it abuse?' show frequent instances of hesitation in the attempt to comprehend if users' particular situations should be considered abusive for the rest of the online community. Interesting information can also be obtained by observing the distribution of the pronoun you. Although the nature of the pronoun you in English makes it difficult to differentiate if reference is being made to either singular or plural entities, the increasing tendency of you in 'Life after abuse' can be interpreted as a more consistent attempt to refer directly to potential readers of the post (women in similar situations). In fact, many posts in this final stage adopt a more encouraging nuance when providing support.

Besides, it seems clear that the pronoun he, undoubtedly one of the most common mechanisms to refer to the perpetrator in these online communities, becomes less and less central in these users' discourse when posting in 'Life after abuse'. It could be hypothesised that this may be due to the fact that the perpetrator is given less discursive prominence in the final phase, when abuse seems to be a past event (note the use of the preposition after in the very name of the community) and the social actor responsible for that is gradually replaced. Nonetheless, a rather different interpretation is also feasible if attention is paid to the evolution of the pronoun they. Given the prominence that the third-person plural pronoun gains in SB3 if contrasted to SB1, this could be also understood as a discursive collectivisation of the perpetrator. To put it differently, there may be a discursive drift from representing the perpetrator in individual terms (he) to collective ones (they), which may have been partly influenced by the mere use of the forum itself and to the process of generating a stronger bond (favouring references of $u s$ as women users against them, the perpetrators). Nonetheless, as it usually happens when working with decontextualised instances of data, a more qualitative exploration of the text would be required to pin down the social actors behind these referential devices (since he could refer to a male child and they can also possibly stand for my friends).

\subsection{Analysing emotionality: positive and negative emotions}

Studies combining linguistic analyses and psychological processes within major social phenomena have proved that LIWC is capable of 
providing accurate identification of emotion in language use (Tausczik and Pennebaker, 2004; Kahn et al., 2007). This research is driven by the assumption that the different degrees and mechanisms in which people express their emotions are fundamental to comprehend how they are experiencing the world (Tausczik and Pennebaker, 2004). Not surprisingly, LIWC has been applied to the exploration of emotionality in trauma and health discourses in different contexts, such as cancer (Bantum and Owen, 2009) or relationship narratives (Boals and Klein, 2005). Moreover, there have been attempts to examine narratives by IPV survivors (Holmes et al., 2007). Although the analysis was based on 32 volunteers in non-CMC contexts, a LIWC scan found that making use of more positive and negative emotion words to talk about their experiences with violence prompted increased feelings of physical pain over the writing sessions, concluding that the higher use of emotion words, the more the perceived immersion in the traumatic event.

LIWC measurements for emotionality in the corpus under inspection are depicted in Table 4 below. Broadly speaking, LIWC is able to identify emotions in two broad spectra: positive and negative emotions. More specifically, it can detect three subtypes of negative emotions (anxiety, anger and sadness). As Table 4 shows, the amount of positive emotions increases within 'Life after abuse' if compared to 'Is it abuse?' $(+0,71 \%)$. Conversely, the percentage measuring negative emotions decreases in the third community if compared to the first one $(-0,22 \%)$, although this decrease would be even more significant if the second community was to be taken into account $(-0,34 \%)$. Curious results can be observed if the type of negative emotions is compared. Accordingly, words measuring 'anxiety' escalate from SB1 to SB2 $(+0,10 \%)$, although a higher peak is observed in SB2 (+0,15\%). With regard to 'anger', however, percentages decline if 'Life after abuse' and 'Is it abuse?' are compared (-0,24\%). Interestingly, the percentages measuring the output for sadness show a more stable distribution across the three communities, finding a slight deviation from the final to the initial stage $(-0,01 \%)$.

These results yield thought-provoking interpretations. On the one hand, especially judging from the observed deviation in percentages found SB1 and SB3, the emotional tone across these communities seems to be arguably distinctive. Thus, whereas lexical choices categorised as positive are more salient in 'Life after abuse', a more negative nuance is perceived in 'Is it abuse?'. This is a somewhat expected 
finding, since more a more optimistic sort of narrative was more likely to permeate the overall discursive scheme within this community. This gains more prominence if posts within this community are analysed in qualitative terms, as they are generally characterised by very supportive messages who seek to give encouragement to other users at this stage. As opposed to this, a more negative emotional tone takes over within the first community, which again is understandable bearing in mind that many of these users take advantage of this community to share their experiences so that other users can share their views on the abusive character of these situations.

\begin{tabular}{|c|c|c|c|c|c|}
\hline \multirow{2}{*}{$\begin{array}{c}\text { Forum } \\
\text { communities }\end{array}$} & \multicolumn{5}{|c|}{ Emotionality (LIWC) } \\
\cline { 2 - 6 } & POSEMO & NEGEMO & ANX & ANGER & SAD \\
\hline $\begin{array}{c}\text { SB1 } \\
\text { 'Is it abuse?' }\end{array}$ & 2,03 & 3,81 & 0,67 & 1,32 & 0,79 \\
\hline $\begin{array}{c}\text { SB2 } \\
\text { 'Getting out' }\end{array}$ & 2,27 & 3,47 & 0,82 & 1,11 & 0,72 \\
\hline $\begin{array}{c}\text { SB3 } \\
\text { 'Life after } \\
\text { abuse' }\end{array}$ & 2,74 & 3,59 & 0,77 & 1,08 & 0,78 \\
\hline
\end{tabular}

Table 4. Analysing emotionality with LIWC (in \%)

On the other hand, the evolution of more nuanced negative emotions is worth alluding to. Unlike a more even distribution of lexical items across the three communities belonging to the category 'sad' according to LIWC, a somewhat divergent tendency is perceived should the focus be on 'anxiety' and 'anger'. In fact, based on the results illustrated in Table 4 above, lexical choices suggesting a higher degree of anxiety reach its peak in 'Getting out'. This may imply that women undergoing IPV may feel more anxious when, having acknowledged they are being abused, they are in the process of leaving the abusive relationship. However, traces of 'anger' in the corpus under scrutiny seem to be more present at an initial stage (SB1), decreasing gradually if the final phase (SB3) is regarded. 


\subsection{Acting in particular ways: the drives behind these forum users}

Although slightly less covered by previous studies using LIWC, another interesting set of categories is the one amalgamated into the umbrella term 'drives' (Pennebaker et al., 2015). Broadly speaking, LIWC attempts to offer insights into the feelings that make language users act in particular ways. Five subcategories are considered for these purposes, relying upon lexical items which are namely included here: affiliation (ally, friend, social), achievement (win, success, better), power (superior), reward (take, prize, benefit) and risk (danger, doubt) (Pennebaker et al., 2015).

LIWC analysis around these forum users' drives are summarised in Table 5 below. As suggested, lexical items measuring the degree of affiliation decrease in 'Life after abuse' if compared to 'Is it abuse?' $(-0,08 \%)$, although not remarkably. The different measurement is equally slight if 'achieve' is taken into account, with a rather stronger tendency in SB3 than in SB1 $(+0,07 \%)$. Steadier divergences are encountered however if the remaining three categories are analysed. When it comes to quantifying levels of 'power' as encapsulated by the lexical choices across the three communities, a more significant difference is found in SB3 if the two previous stages are contrasted $(+0,30 \%$ if compared to $\mathrm{SB} 1,+0,44 \%$ if the same is done with SB2). A higher percentage is also observed in 'Life after abuse' as far as 'reward' is concerned $(+0,26 \%)$. Contrary to this tendency, lexical choices measuring 'risk' seem to be less noticeable in SB3 if set against SB1 (-0,24\%).

\begin{tabular}{|c|c|c|c|c|c|}
\hline \multirow{2}{*}{$\begin{array}{c}\text { Forum } \\
\text { communities }\end{array}$} & \multicolumn{5}{|c|}{ Drives (LIWC) } \\
\hline & $\begin{array}{l}\text { AFFILIA- } \\
\text { TION }\end{array}$ & ACHIEVE & POWER & REWARD & RISK \\
\hline $\begin{array}{c}\text { SB1 } \\
\text { 'Is it abuse?' }\end{array}$ & 2,54 & 1,06 & 2,30 & 1,18 & 0,95 \\
\hline $\begin{array}{c}\text { SB2 } \\
\text { 'Getting out' }\end{array}$ & 2,32 & 1,13 & 2,16 & 1,34 & 0,79 \\
\hline $\begin{array}{c}\text { SB3 } \\
\text { 'Life after } \\
\text { abuse' }\end{array}$ & 2,46 & 1,13 & 2,60 & 1,44 & 0,71 \\
\hline
\end{tabular}

Table 5. Forum users' drives according to LIWC (in \%) 
As suggested by the percentages above, some of these areas show a degree of divergence that may suggest significant alterations in the discursive characterisation of the online communities explored for this study. One of the categories that particularly catches my attention is the one linked to power. As pointed out in the first subsection of this chapter above, obtaining a minor percentage in the category 'clout' in the third subcorpus can be interpreted as a characteristic of more tentative, humble or even anxious style in SB3. This interpretation seems to be at odds if closer attention is paid to the evolution of lexical choices fitting in the 'power' category. In fact, such firm increase $(+0,30 \%$ SB3 to $\mathrm{SB} 1,+0,44 \% \mathrm{SB} 3$ to SB2) would respond to my original expectations, which presumed traces of empowered discourse in the 'Life after abuse'. In a similar vein, this trend would also be reinforced by examining the evolution of risk. Lexical choices connected to risk within SB3 are less significant if contrasted with SB1, which would again match my original expectations when equating the 'Is it abuse?' with a stage that is characterised for a higher presence of risks and challenges for women undergoing IPV.

\section{Concluding remarks}

This article has sought to demonstrate how a software tool for quantitative text analysis (LIWC) can effectively be employed to provide corpus-driven insights into the micro-level of discourse by an online community of women who have at some point experienced IPV in their lives. This study has made use of some of the most relevant linguistic categories measured by LIWC to investigate the discursive frames that characterise three online communities within an online forum that offers its users the chance of engaging in narratives that seek to provide assistance and help to other users that participate in this online environment. It is worth recalling a key research question in this article was to explore the ways in which the application of text-analysis software tools such as LIWC can contribute to better understand the online discourse of women undergoing IPV-related experiences. For this purpose, and by scrutinising the output measures provided by LIWC (in percentages), results have showed how collective identity is forged within these three online communities and the ways in which this permeates in the discourse they use. These findings are of particular relevance 
if framed within the socio-cognitive approach to discourse, tenets of which are also highlighted.

Exploring the possible ways in which LIWC-provided categories can shed light on the discursive characterisation of the three online communities investigated in this paper was another central research question. With this in mind, having incorporated the analysis provided by LIWC, interesting observations have been found. As suggested elsewhere, users in 'Is it abuse?' are remarkably characterised for a negative emotional tone, which becomes more positive in 'Life after abuse'. Additionally, users within 'Life after abuse' seem to express themselves in more personal and humble ways, which is justified by a higher percentage in the category measuring authenticity. The fact that LIWC is capable of offering a detailed account of pronominal distribution in a given corpus paves the way for reaching fascinating conclusions based on the usage of pronouns. Although more qualitative explorations would be crucial to reinforce the validity of these arguments, the decreasing tendency when using the third-person singular pronoun (he) in 'Life after abuse' may prove that discourses around the perpetrator weaken in the third community. Nevertheless, based again on the percentage that LIWC offers for the third-person plural pronoun (they) another feasible interpretation would view this changing pattern as a process of collectivisation of the perpetrator. Thus, influenced by exposure to socio-cognitive representations of the perpetrator in the forum, users can be said to move from an individualised referential strategy (he) to a collective one (they). Furthermore, LIWC can also provide assistance when measuring lexical emotionality. As argued above, there seems to be a divergence in the ways in which negative emotions evolve if the three corpora are contrasted. Whereas lexical indicators of sadness prove to be more uniform across the three communities, pointers of anxiety seem to be more pervasive at intermediates stages ('Getting out') than at first ones, while the ones that measure anger are more likely to occur at the outset. Quite relatedly, the use of LIWC can also be used to suggest a gradual discursive empowerment in users writing in 'Life after abuse', which may somewhat mirror a change also behavioural terms at this final stage.

Useful though these pointers may be to build bridges between the micro and the macro levels of discourse, results deriving solely from quantitative explorations need to be treated with due precaution. As 
stated by main developers of LIWC itself, "the study of word use as a reflection of psychological state is in its early stages" (Tausczik and Pennebaker, 2010:30). This is one the reasons why future research in this field could aim at incorporating similar text-analysis tools such as Lingmotif (Moreno-Ortiz, 2016) to investigate these tools and their different affordances may trigger complementary results. In any case, although the incorporation of corpus-driven approaches to discourse analysis has shown to be efficient to build language analyses upon more empirically-based findings, the limitations of corpus linguistics need to be considered and addressed. As already mentioned, making strong claims on the basis of pronoun usage may trigger misleading interpretations of any discursive event. Together with context, software tools are still not well-equipped with mechanisms to deal with figurative language or ironic and sarcastic references. Consequently, studies aiming at providing a holist view of a discursive phenomenon should always leave room for qualitative examinations, which can usually account for many of the already-mentioned drawbacks.

\section{Acknowledgements}

This research is funded by the Spanish Ministry of Education (FPU1304471). I would also like to thank both reviewers for their interesting comments and observations, which I have incorporated in the final version of this paper. Likewise, my wholehearted gratitude to the editors of this volume for their editorial initiative and their admirable hard work when compiling all the contributions in a very comprehensive harmony.

\section{References}

Ali, Parveen Azam \& Naylor, Paul. 2013. Intimate partner violence: A narrative review of the feminist, social and ecological explanations for its causation. Aggression and Violent Behavior 18(6): 611-619. doi: https://doi.org/10.1016/j.avb.2013.01.003

Anthony, Lawrence. 2011. AntConc (Version 3.2. 2)[Computer Software]. Tokyo: Waseda University.

Augoustinos, Martha; Walker, Iain \& Donaghue, Ngaire. 2006. Social Cognition: An Integrated Introduction ( $\left.2^{\text {nd }} e d.\right)$. London: Sage.

Baker, Paul. 2006. Using Corpora in Discourse Analysis. London: Continuum. 
Baker, Paul. 2008. Sexed texts: Language, Gender and Sexuality. London: Equinox.

Baker, Paul; Gabrielatos, Costas; Khosravinik, Majid; Krzyżanowski, Michał; McEnery, Tony \& Wodak, Ruth. 2008. A useful methodological synergy? Combining critical discourse analysis and corpus linguistics to examine discourses of refugees and asylum seekers in the UK press. Discourse \& Society 19(3): 273-306. doi:10.1177/0957926508088962

Bantum, Erin O'Carroll \& Owen, Jason. 2009. Evaluating the validity of computerized content analysis programs for identification of emotional expression in cancer narratives. Psychological Assessment 21(1): 79. doi: 10.1037/a0014643

Boals, Adriel, \& Klein, Kitty. 2005. Word use in emotional narratives about failed romantic relationships and subsequent mental health. Journal of Language and Social Psychology 24(3): 252-268. doi: $10.1177 / 0261927 \mathrm{X} 05278386$

Boonzaier, Floretta. 2008. "If the man says you must sit, then you must sit." The relational construction of woman abuse: Gender, subjectivity and violence. Feminism \& Psychology 18(2): 183-206. doi: https://doi. org/10.1177/0959353507088266

Baly, Andrew. 2010. Leaving abusive relationships: Constructions of self and situation by abused women. Journal of Interpersonal Violence 25(12): 2297-2315. doi: https://doi.org/10.1177/0886260509354885

Bou-Franch, Patricia. 2013. Domestic Violence and Public Participation in the Media: The Case of Citizen Journalism. Gender and Language 7(3): 275-302. doi: 10.1558/genl.v7i3.275

Burguess, Anne \& Crowell, Nancy. 1996. Understanding violence against women. Washington: National Academy Press.

Campbell, Jacquelyn. 2002. Health consequences of intimate partner violence. The Lancet 359(9314): 1331-1336. doi: http://dx.doi.org/10.1016/ S0140-6736(02)08336-8

Cohn, Michael; Mehl, Matthias \& Pennebaker, James. 2004. Linguistic Markers of Psychological Change Surrounding September 11, 2001. Psychological Science 15: 687-693. doi: 10.1111/j.0956-7976.2004.00741.x

Dartnall, Elizabeth \& Jewkes, Rachel. 2013. Sexual violence against women: the scope of the problem. Best Practice \& Research Clinical Obstetrics \& Gynaecology 27(1): 3-13. doi: 10.1016/j.bpobgyn.2012.08.002

Dobash, Rebecca \& Dobash, Russell. 2015. Domestic Violence: Sociological Perspectives. International Encyclopedia of the Social \& Behavioral Sciences $\left(2^{\text {nd }}\right.$ ed.). Elsevier, 632-635. doi: 10.1016/B0-08-0430767/03935-8 
Dutton, Donald \& Nicholls, Tonia. 2005. The gender paradigm in domestic violence research and theory: Part 1, The conflict of theory and data. Aggression and Violent Behavior 10(6): 680-714. doi: 10.1016/j. avb.2005.02.001

Fairclough, Norman. 2015. Language and Power ( $3^{\text {rd }}$ ed.). London: Routledge. Gunsch, Mark; Brownlow, Sarah \& Mabe, Zachary. 2000. Differential forms linguistic content of various of political advertising. Journal of Broadcasting \& Electronic Media 44(1): 27-42. doi: http://dx.doi.org/10.1207/ s15506878jobem4401_3

Harris, Kate; Palazzolo, Kellie, \& Savage, Matthew. 2012. "I'm not sexist, but...": How ideological dilemmas reinforce sexism in talk about intimate partner violence. Discourse \& Society 23(6): 643-656. doi: $10.1177 / 0957926512455382$

Hart, Christopher \& Cap, Piotr (ed.). 2014. Contemporary Critical Discourse Studies. London: Bloomsbury Publishing.

Heise, Lori. 1998. Violence against women an integrated, ecological framework. Violence Against Women 4(3): 262-290. doi: 10.1 177/1077801298004003002

Heise, Lori \& García-Moreno, Claudia. 2002. Violence by intimate partners. In Krug, E.; Dahlberg, L.L.; Mercy, J. A.; Zwi, A. B. \& Lozano, R. (ed.) World Report on Violence and Health. Geneva: World Health Organization, 88-121.

Holmes, Danielle; Alper, Georg; Ismailji, Tasneem; Classen, Catherine; Wales, Talor; Cheasty, Valerie; Miller, Andrew \& Koopman, Cheryl. 2007. Cognitive and emotional processing in narratives of women abused by intimate partners. Violence Against Women 13(11): 1192-1205. doi: 10.1177/1077801207307801

Kacewicz, Ewa; Pennebaker, James; Davis, Matthew; Jeon, Moongee \& Graesser, Arthur. 2013. Pronoun use reflects standings in social hierarchies. Journal of Language and Social Psychology 33(2): 125-143. doi: 10.1177/0261927X13502654

Kahn, Jeffrey; M. Tobin, Renee; Massey, Audra \& Anderson, Jennifer. 2007. Measuring emotional expression with the Linguistic Inquiry and Word Count. The American Journal of Psychology: 263-286. doi: $10.2307 / 20445398$

Kangas, Sara. 2014. What can software tell us about political candidates?: A critical analysis of a computerized method for political discourse. Journal of Language and Politics 13(1): 77-97. doi: 10.1075/jlp.13.1. 04kan

KhosraviNik, Majid. 2010. Actor descriptions, action attributions, and argumentation: towards a systematization of CDA analytical categories in 
the representation of social groups. Critical Discourse Studies 7(1): 5572. doi: 10.1080/17405900903453948

Koller, Veronika. 2008. Lesbian Discourses: Images of a Community. London: Routledge.

Koller, Veronika. 2014. Applying Social Cognition Research to Critical Discourse Studies: The Case of Collective Identities. In Hart, Christopher \& Cap, Piotr (ed.) Contemporary Critical Discourse Studies. London: Bloomsbury, 147-166.

Kowalski, Robin. 2000. “I was only kidding!": Victims' and perpetrators' perceptions of teasing. Personality and Social Psychology Bulletin 26(2): 231-241. doi: 10.1177/0146167200264009

Krug, Etienne; Dahlberg, L.L; Mercy, James; Zwi, Anthony \& Lozano, Rafael (ed.). 2002. World Report on Violence and Health. Geneva, Switzerland: World Health Organization.

Kumar, Anant; Nizamie, S. Haque \& Srivastava, Naveen. 2013. Violence against women and mental health. Mental Health \& Prevention 1(1): 4-10. doi: https://doi.org/10.1016/j.mhp.2013.06.002

LIWC. 2017. Where do the numbers come from? How are they calculated? https://liwc.wpengine.com/interpreting-liwc-output/ [Accessed 22/03/2017].

Markham, Annette \& Buchanan, Elizabeth. 2012. Ethical decision-making and internet research: Recommendations from the AOIR ethics working committee (version 2.0). http://www.dphu.org/uploads/attachements/ books/books_5612_0.pdf [Accessed 21/03/2017].

Marín Arrese, Juana Isabel. 2011. Effective vs. epistemic stance and subjectivity in political discourse: Legitimising strategies and mystification of responsibility. Critical Discourse Studies in Context and Cognition. Amsterdam: John Benjamins, 193-224.

Moreno-Ortiz, A. (2016). Lingmotif 1.0 [Computer Software]. Málaga, Spain: Universidad de Málaga. http://tecnolengua.uma.es/lingmotif.

Newman, Matthew; Pennebaker, James; Berry, Diane \& Richards, Jane. 2003. Lying words: Predicting deception from linguistic styles. Personality and Social Psychology Bulletin 29: 665-675. doi: 10.1177/0146167203029005010

Nicholls, Tonia \& Dutton, Donald. 2001. Abuse committed by women against male intimates. Journal of Couples Therapy 10(1): 41-57. doi: 10.1300/ J036v10n01_04

Nissenbaum, Helen. 2010. Privacy in context: Technology, policy, and the integrity of social life. Stanford: Stanford University Press.

Office for National Statistics. 2015. Intimate partner violence and partner abuse. https://www.ons.gov.uk/peoplepopulationandcommunity/ 
crimeandjustice/compendium/focusonviolentcrimeandsexualoffences/ yearendingmarch2015/chapter4intimatepersonalviolenceandpartnerabuse [Accessed 03/03/2017].

Pennebaker, James; Booth, Roger \& Francis, Martha. 2007. Linguistic Inquiry and Word Count: LIWC [Computer software]. Austin: LIWC.net

Pennebaker, James. 2011. The Secret Life of Pronouns: What Our Words Say About Us. New York: Bloomsbury.

Pennebaker James; Chung, Cindy; Frazee Joey, Lavergne Gary \& Beaver, David. 2014. When small words foretell academic success: The case of college admissions essays. PLoS ONE 9(12): e115844. doi: https://doi. org/10.1371/journal.pone.0115844

Pennebaker, James; Boyd, Ryan; Jordan, Kayla \& Blackburn, Kate. 2015. The development and psychometric properties of LIWC2015. Texas: The University of Texas. doi: 10.15781/T29G6Z

Robinson, Rebecca; Navea, Reanelle \& Ickes, William. 2013. Predicting final course performance from students' written self-introductions: A LIWC analysis. Journal of Language and Social Psychology 32(4): 469-479. doi: 10.1177/0261927X13476869

Rude, Stephanie; Gortner, Eva-Maria \& Pennebaker, James. 2004. Language use of depressed and depression-vulnerable college students. Cognition \& Emotion 18(8): 1121-1133. doi: 10.1080/02699930441000030

Santaemilia, José \& Maruenda, Sergio. 2014. The linguistic representation of gender violence in (written) media discourse. Journal of Language Aggression and Conflict 2(2): 249-273

Shipley, Thomas \& Zacks, Jeffrey (ed.). 2008. Understanding Events. From Perception to Action. Oxford: Oxford University Press.

Simmons, Rachel; Gordon, Peter \& Chambless, Dianne. 2005. Pronouns in Marital Interaction What Do "You" and "I" Say About Marital Health? Psychological science 16(12): 932-936. doi: 10.1111/j.14679280.2005.01639

Slatcher, Richard; Chung, Cindy; Pennebaker, James \& Stone, Lori. 2007. Winning words: Individual differences in linguistic style among US presidential and vice presidential candidates. Journal of Research in Personality 41(1): 63-75. doi: 10.1016/j.jrp.2006.01.006

Stokoe, Elizabeth. 2010. "I'm not gonna hit a lady": Conversation analysis, membership categorization and men's denials of violence towards women. Discourse \& Society 21(1): 59-82. doi: http://dx.doi. org/10.1177/0957926509345072

Stubbs, Michael. 1997. Whorf's children: critical comments on critical discourse analysis. In Ryan, Ann \& Wray, Alison (ed.) Evolving Models of Language. Clevedon: Multilingual atters, 100-116. 
Sunderland, Jane \& Litosseliti, Lia. 2002. Gender identity and discourse analysis: Theoretical and empirical considerations. Gender Identity and Discourse Analysis. Amsterdam: John Benjamins, 1-39.

Tausczik, Yla \& Pennebaker, James. 2010. The psychological meaning of words: LIWC and computerized text analysis methods. Journal of Language and Social Psychology 29: 24-54. doi: https://doi. org/10.1177/0261927X09351676

Van Dijk, Teun. 1993. Elite Discourse and Racism. London: Sage.

Van Dijk, Teun. 2014. Discourse-Cognition-Society. Current state and prospects of the Socio-Cognitive Approach to Discourse. In Hart, Christopher \& Cap, Piotr (ed.) Contemporary Critical Discourse Studies. London: Bloomsbury, 121-146.

Van Dijk, Teun. 2015. Racism and the Press. London: Routledge.

Walby, Sylvia; Towers, Jude; Balderston, Susan; Corradi, Consuelo; Francis, Brian; Heiskanen, Markku; Helweg-Larsen, Karin et alii (ed.) 2017. The Concept and Measurement of Violence against Women and Men. Bristol: Policy Press.

Walker, Lenore. 2015. Looking back and looking forward: Psychological and legal interventions for domestic violence. Ethics, Medicine and Public Health 1(1): 19-32. doi: 10.1016/j.jemep.2015.02.002

Widdowson, Henry. 2004. Text, Context, Pretext: Critical Issues in Discourse Analysis. Oxford: Blackwell

Winstok, Zeev \& Sowan-Basheer, Wafa. 2015. Does psychological violence contribute to partner violence research? A historical, conceptual and critical review. Aggression and Violent Behavior 21: 5-16. doi: 10.1016/j.avb.2015.01.003

Wodak, Ruth \& Fairclough, Norman. 2004. Critical discourse analysis. Qualitative Research Practice: Concise Paperback Edition. 185-202.

Wodak, Ruth \& Meyer, Michael. 2009. Methods for Critical Discourse Analysis. London: Sage

World Health Organization. 2016. Violence Against Women. Geneva: World Health Organization. http:/www.who.int/mediacentre/factsheets/ fs239/en/ [Accessed 07/03/2017]. 
